\title{
Spiritual Intelligence and Business Environments
}

\author{
Fadil Mušinović \\ Faculty of Commercial and Business Sciences, Slovenia \\ fadil.musinovic@siol.net
}

The article combines two development-oriented concepts, spiritual intelligence and business systems, composed of four elements. Spiritual intelligence, according to King (2008), consists of critical existential thinking, production of personal meaning, transcendental awareness, and conscious state expansion. Business systems, according to Bulc (2006), evolve evolutionarily in four stages, from the working environment, through the learning and thinking environments, to the conscious environment. The purpose of the study was to determine whether the factors of spiritual intelligence are related to the developmental stages of business systems and whether they differ in the various developmental stages of business systems. The empirical data was collected electronically, using a composite questionnaire in different business environments. 601 employees participated in the study. The results showed positive correlations between the factors of spiritual intelligence and learning, thinking, and the conscious environment, but no correlation to the working environment. In various development stages of business systems, certain differences have been revealed between the factors of spiritual intelligence. Regarding spiritual intelligence and business environments, the research has also shown differences based on gender, work experience, and the level of education.

Keywords: spiritual intelligence, evolution, business environments, individual, development

(cc)BY-SA https://doi.org/10.26493/2335-4194.13.167-177

\section{Introduction}

Intelligence has been evolving as a discipline through different milestones. The beginnings of research date back to the age of Plato and Aristotle (see http://www .intelltheory.com), while the one of the first scientific definitions dates back to the end of the 18th century. That is when Galton tried to measure the basic abilities of the mind through sensory discrimination and reaction times (Jensen, 2002). Later on, James Cattell broadened Galton's work with psychological testing and by using surveys and questionnaires, targeted at studying intelligence (Cianciolo \& Sternberg, 2004). The next milestone was the work of two French psychologists, Alfred Binet and Theodore Simon, who have developed an objective test for mea- suring a child's intelligence, while the development in this direction led to Terman's adaptation of the test and the use of the IQ. In comparison to the individual tests, the Army alpha and Army beta group tests can also be considered as milestones (Detterman, 2009).

The consequence of such a long period of study is an abundance of definitions, in which each offers their own aspect (e.g. the classical aspect, the biological aspect) in defining the intelligence of a person in a slightly different way. For Gottfredson (1998), intelligence is an individual's ability to deal with cognitive complexity, for Sternberg and Salter (1982), intelligence is goal-oriented and environmentally-adjustable behaviour, while the Merriam Webster Dictionary (https://www.merriam-webster.com) states that intel- 
ligence is the ability to learn and understand or work or try to work in new situations; skillful use of reasoning; the ability to use knowledge to manage one's environment; or abstract thinking, as is measured with objective criteria (e.g. tests). Different reasoning and arguments of what intelligence is and is not has gone so far, that a group of 52 scientists signed a statement in December 1994, declaring what intelligence is and what it is not (Gottfredson, 1997).

The spirituality of an individual has also been researched relatively well, as it has been studied since the time of William James (1902), who believed that our spiritual experiences have the potential to broaden and deepen our lives. However, there are more definitions of what spirituality is. Some authors define spirituality as an inner instinct (Emmons, 2000), while others define it as a sequence of topmost experiences and transcendent moments (MacDonald, 200o). But some authors believe that spirituality is represented as an integration of both the inner instinct as well as topmost experiences (Coyle, 2002; George et al., 2000; Vaughan, 2002).

Historically, spirituality was not separate from religious experiences, but nevertheless some theorists believe that key differences between religion and spirituality do exist (Del Rio \& White, 2012). The thought that spirituality could be a form of intelligence was developed with the theory of multiple intelligences (Gardner, 1995). In this theory, intelligence is a series of connected and, at the same time, separate cognitive processes and abilities that allow us to understand the world, our development, and our improvements. It is also the ability to solve problems in different fields of human activity. In his own theory, Gardner (1995) speaks of multiple intelligences: the lingual, logical-mathematical, spatial, musical, motor, interpersonal, and inner personal intelligence. The author first thought that spirituality cannot be a form of intelligence, but later changed his mind. He added a new type of intelligence, the existential or moral intelligence (Gardner, 2000), which has the characteristics of spiritual intelligence (Emmons, 2000; King, 2008; King \& DeCicco, 2009; Vaughan, 2002). It includes different development processes and adapts to a human's life (Gardner, 1995).
Spiritual intelligence, as defined in this paper, is not spiritually inspirational or religious identity and practice. If we possess spiritual intelligence, we do not require a belief system linked to religion, and we are not required to identify ourselves as a spiritual person (King, 2008).

Spiritual intelligence is, just like general intelligence (where we measure the person's IQ), differently defined. According to Emmons (2003, p. 176), spiritual intelligence is 'an adaptive use of spiritual information with the purpose of easing daily problem solving and reaching set goals.' It is composed of the ability to transcend the physical and material, the experience of a heightened state of consciousness, dedication to daily experiences, and the use of spiritual resources to solve problems.

Vaughan (2002) states that spiritual intelligence, along with self-awareness, also means that we are aware of our own relationship to the excess in regards to the Earth and to all living beings.

On the other hand, Zohar and Marshall (200o, p. 3) believe that spiritual intelligence 'enables people to be creative, to change the rules, and to change their situations. It enables us to play with boundaries, it gives us moral meaning, it enables us to confront the questions of good and evil, and enables us to imagine the unrealized possibilities.'

Wolman (2001, p. 84) established that spiritual intelligence is 'a human capacity for asking final questions about the purpose of life and, at the same time, a capacity to embrace these questions in experiencing seamless connections between all of us and the world, in which we live in.'

King and DeCicco (2009, p. 69) have defined spiritual intelligence as 'a collection of mental capacities, which contribute to awareness, integration, and adjustment of immaterial and transcendent aspects of an individual's existence, which lead to consequences, such as: critical existential thinking, producing personal meaning, transcendent awareness, and conscious state expansion.' Reaching and experiencing these spiritual abilities is supposed to - while taking into account Gardner's criteria for measuring and determining the field of intelligence - strengthen the quality of an individual's life (Gardner, 1995; 2000). 
The quality of an individual's life can be strengthened within different contexts. We can, for example, strengthen it at home, in a business environment or in other social systems in which we are included in our life, as these social systems influence our lives and our spiritual intelligence (Yang \& Wu, 2009). The influence can differ. For example, Schneider (1987) states that the influence between the social system and the individual is mutual. According to the theory (model) of ASA - Attraction - Selection - Attrition, social systems attract certain types of people, in which, if they get along with the system or organisation, they stay based on selection, or leave it later on.

Business systems are also social systems. In these systems we conduct our work and go about our business. Structurally they are diverse; they can be, for example, hierarchical (e.g. the police, the military, the fire brigade), or they can be flatter (e.g. Google), but compared to personal, family, and leisure social systems, they are different. People, with whom we socialise there, are different. The way of thinking and behaving is different. Even goals that we follow with the context of business systems are different.

Business systems can be understood as living beings, or at least they have some characteristics of living beings: they have their own evolutional dynamic, history, present, and future; they are independent organisms with feelings, fears, and dreams; they have their own mission, goals, and life span. They differ among each other and at the same time they are connected, because 'for each new phase [stage] it is absolutely necessary to possess the vital forces of its predecessors' (Bulc, 2006, p. 20).

According to Bulc (2006), the development of business systems encompasses four development stages: the working environment, the learning environment, the thinking environment, and the conscious environment. These stages run in sequence, by business rules, resources, and leverages. Between the stages there are transitional transformational periods of conduct, in which it comes to disorders or dialectical fights between the old and the new (e.g. dialectical fight between the working and the learning environment).

The working environment is the first developmental stage of business systems. Added value in this sys- tem is created with diligent work, which results in creating a product as the key part of the working process. Work is conducted through manufacture; it is partly automated and computerised. Methods for systematic cost management are developed to some extent, including the optimisation of support services. The key competitive advantage is the productivity and its constant increase.

The second developmental stage - the learning stage - is characterised by added value that is created with knowledge. Diligence, which posed as added value in the previous stage, does not suffice anymore in this stage. It needs to be upgraded with knowledge, which is accumulated in ever more accessible literature that, through in-depth studies, enables bigger productivity management. As a consequence, the difference in productivity between individual companies gets smaller, which by itself demands a different type of added value or a different competitive advantage. The latter is seen in this stage in knowledge, which also manifests itself in the quality of the product. In this developmental period the key observed item is not the product or the emotional attachments of workers and managers to the product, but the customers, who think the product is interesting and, later on, buy it. Or they decide not to buy it. In relation to this - comparatively with the working environment - the work processes also change. These are based on knowledge and change through time or circle through constant improvements. In consequence, the management process, interpersonal relations, work organisation, values, etc. also comparatively change or develop.

Creativity brings added value into the thinking environment, while the key element is innovation. Quality is improving comparatively with the learning environment, while the improvements are based on creative innovations, which are unknown and different. A growing emphasis is given to the individual and the inter-functional teams, which can only function in relaxed and dynamic environments, where there is enough time to think and get creative ideas. It is also important to collaborate with the environment, where, in a mix of hard work, knowledge, and thinking, new ideas and innovative processes arise, which the market or the environment need. 
The conscious environment is the last developmental stage. It represents a growing humanisation of work; added value is represented by intuitiveness in deep connection with spirituality. The key factor is the life energy of the individual, group, or company, values and informal forms of collaboration with the environment.

The researched topic is in our opinion scientifically relevant, because spiritual intelligence is an interesting and poorly researched concept, especially in the context of developmental stages of business systems, which was the main purpose and goal of this paper. We wanted to determine whether there is a connection between spiritual intelligence and developmental stages of business environments, what kind of connection it is and also, whether spiritual intelligence is different in various stages of business systems and, if it is, what are the differences.

Given that such research has not been conducted yet, we based the logic of establishing hypotheses from links in the content of cited papers. We checked two hypotheses:

$\mathrm{H} 1$ In higher developmental stages of business systems employees have a more developed spiritual intelligence.

$\mathrm{H} 2$ Spiritual intelligence is significantly different in individual developmental stages of business systems.

\section{Method}

The research was done through the usual steps; the first part was theoretical and intended for reviewing literature and previous research, and forming theoretical fundamentals based on known concepts. Descriptive, compilation, comparative, and analysis and synthesis methods were used in this part.

In the second - the empirical part, validity, reliability, objectivity, and other measurable characteristics of the tools used were introduced. Later, results were introduced and explained, after which discussion follows.

\section{Respondents}

The sample was opportunistic and self-selective. 615 people chose to participate. 14 questionnaires were dis- carded from the survey, as they were either blank or participants answered every question with the same values, therefore, they were useless for the purposes of the survey.

601 questionnaires were used in the survey. 227 (37.8 \% of the sample) men and 372 (61.9\%) women participated. Two participants did not mark their genders. This represented $0.3 \%$ of all included questionnaires.

Participants were 18 to 70 years old. The average age was 40 years. Five individuals did not disclose their age. Age data was divided into categories of 10 years. The categories were: under 20 years, $20-30$ years, $30-$ 40 years, $40-50$ years, 50-60 years, and 60-70 years. Due to the fact that there were only 4 participants under the age of 20, we put them into the category 20-30 years. There were $132(22 \%)$ individuals in this category. The category $20-30$ years included 207 (34.4\%) individuals. The category 40-50 years included 163 (27.1\%) individuals. The category $50-60$ years included 76 (12.6\%) individuals. The last category included 18 (3\%) participants.

Years of work experience of participants varied from o to 47 years. 13 participants did not disclose this information. The data was divided into categories of 10 years; from o to 10 , from 11 to 20 , from 21 to 30 , from 31 to 40 , and from 41 to 50 years. The first category included 192 (31.9\%) participants. The category 11-20 included 184 (30.6\%) individuals. The category 21-30 included 134 (22.3\%) participants. The following category was $31-40$. This category included $70(11.6 \%)$ individuals. The last category included 8 (1.3\%) participants.

Based on education, the participants were divided into these groups: 3 (0.5\%) participants had primary education, 102 (17\%) had secondary education, 178 (29.6\%) participants had the first Bologna level of education, 252 (41.9\%) participants had the second Bologna level of education, while $60(10 \%)$ individuals had the third Bologna level of education. $6(1 \%)$ participants did not disclose their education level.

523 ( $87 \%$ of the sample) participants were employed, $40(6.7 \%)$ were students, $20(3.3 \%)$ were retired, while 16 (2.7\%) were unemployed. 2 (0.3\%) participants did not disclose their employment status. 


\section{Tools}

We used a questionnaire in our survey and have named it Spiritual intelligence (sQ) in business environments (Po). It was composed of two different sources. We used the Spiritual intelligence self-report inventory SISRI-24 (King, 2008; King \& DeCicco, 2009) for the part regarding spiritual intelligence, while for the part regarding business environments we used our own four items that were produced based on Bulc's (2006) statements. The questionnaire included 28 items and demographic data. The Cronbach alpha for the 50 stated items was 0.908.

The Spiritual Intelligence Self-Report Inventory SISRI-24 (King, 2008; King \& DeCicco, 2009) measures two kinds of abilities and skills: critical existential thinking, personal meaning production, transcendent awareness, and conscious state expansion. For this we used the 5-point Likert scale with 1 meaning is not true at all' and 5 meaning 'absolutely true.' The Cronbach alpha for all 24 items was 0.944; for the 7-item factor 'critical existential thinking' the Cronbach alpha was 0.874 , for the 5 -item factor 'personal meaning production' it was 0.817 , for the 7 -item 'transcendent awareness' it was 0.736 , and for the 5 -item 'conscious state expansion' it was 0.888 .

The following were four items of our own designed questionnaire for measuring the evolutionary developmental stage of business environments, which was designed based on the theory (Bulc, 2006). The questionnaire is composed of four items: the working environment, the learning environment, the thinking environment, and the conscious environment. We used a 3-point scale, where 1 means 'does not apply to us,' 2 means 'partly applies to us, and 3 means 'it applies to us almost entirely. The Cronbach alpha for the abovementioned items was 0.630 .

\section{Procedures}

Data was collected with an electronic questionnaire with the help of Google docs tools. For data gathering we used snowball non-random sampling (Biernacki \& Waldorf, 1981; Faugier \& Sergeant, 1997) that took place via various organisation managements.

The link to the questionnaire was sent to various email addresses with included requests that the e-mail recipients participate in the survey and share the invitation to the survey through their social networks their friends, acquaintances, coworkers, etc.

The gathered forms were then exported to the relevant format for later processing in the SPss software (Statistical Package for Social Sciences). The database was also refined in order to obtain more stable results for processing. First, we discarded the 9 blank questionnaires. After that structural analysis followed. Based on this analysis, we also removed 5 questionnaires that had the same value filled out in all the questions (e.g. all the items had the value 3 ). The remaining 601 were then included in the statistical analysis.

The statistical analysis was then conducted according to the instructions for each concept. So, for the analysis regarding spiritual intelligence it was taken into account that the overall result, after the reverse coding of the 6th item is done, is the sum of all answers on the items. We named it Spiritual intelligence and marked it with $s \mathrm{Q}$. We have also taken into account that the higher the result, the higher is the level of spiritual intelligence or individual capacities (King, 2008). The items in Spiritual intelligence were divided into 4 factors based on factor analysis (King, 2008), namely:

1. The factor critical existential thinking - abbreviated as CET - was calculated by summing the seven items which, according to King (2008), fall into this category. These items are 1, 3, 5, 9, 13, 17, and 21.

2. The factor personal meaning production - abbreviated as PMP - was calculated by summing the five items which, according to King (2008), fall into this category. These items are 7, 11, 15, 19, and 23.

3. The factor transcendent awareness - abbreviated as TA - was calculated by summing the seven items which, according to King (2008), fall into this category. These items are 2, 6 (reverse coding), 10, 14, 18, 20, and 22.

4. The factor conscious state expansion - abbreviated as CSE - was calculated by summing the five items which, according to King (2008), fall into this category. These items are 4, 8, 12, 16, and 24. 
The evolutionary development of business environments - abbreviated as POK - is covered in one item that was designed based on the questionnaire results. It was done so that from a collection of four evolutionary development stages we added up the raw results and divided them into individual categories or stages of the evolutionary development. Consequently, the values 4 and 5 were classified into the work business environment, 6 and 7 into the learning business environment, 8 and 9 into the thinking business environment, and 10, 11, and 12 were classified into the conscious business environment. The evolutionary development of business environments is also defined through individual developmental stages of business systems, namely 4 variables, named after the developmental stages: the working environment, the learning environment, the thinking environment, and the conscious environment.

\section{Results}

Table 1 shows the correlation between spiritual intelligence (sQ) and its factors critical existential thinking (СET), personal meaning production (PMP), transcendent awareness (TA), conscious state expansion (CSE), and the evolutionary developmental stages of business systems - work, learning, thinking, and conscious environment.

The table also shows a statistically significant positive correlation between the learning environment and spiritual intelligence ( $\mathrm{s} Q$ ) and its factors critical existential thinking (СЕT), personal meaning production (Р МP), transcendent awareness (TA) and conscious state expansion (CSE). A statistically significant positive correlation is also shown between the learning environment and spiritual intelligence ( $\mathrm{s} Q$ ) and its factors critical existential thinking (CET), personal meaning production ( $\mathrm{PM}$ ), transcendent awareness (TA) and conscious state expansion (CSE). There is also a statistically significant positive correlation between the conscious environment and spiritual intelligence $(\mathrm{s} Q)$ and its factors critical existential thinking (CET), personal meaning production ( $\mathrm{PMP}$ ), transcendent awareness ( $\mathrm{TA})$ and conscious state expansion (CSE).

In the first column the table shows that the corre-
Table 1 Correlation between Spiritual Intelligence and Developmental Stages of Business Systems

\begin{tabular}{lrccc}
\hline Item & $(1)$ & $(2)$ & $(3)$ & $(4)$ \\
\hline SQ & -0.047 & $0.184^{\star *}$ & $0.108^{\star}$ & $0.104^{\star}$ \\
CE T & -0.039 & $0.122^{\star *}$ & 0.060 & 0.041 \\
PMP & -0.060 & $0.168^{\star *}$ & $0.130^{\star *}$ & $0.141^{\star *}$ \\
TA & -0.064 & $0.160^{\star *}$ & $0.102^{\star}$ & 0.075 \\
CSE & 0.026 & $0.148^{\star *}$ & $0.102^{\star}$ & $0.140^{* *}$ \\
\hline
\end{tabular}

Notes Column headings are as follows: (1) working environment, (2) learning environment, (3) thinking environment, (4) conscious environment. $N=601$. Displayed are the derived variables $S Q$ - spiritual intelligence, CET - critical existential thinking, PMP - personal meaning production, TA - transcendent awareness, CSE - conscious state expansion and individual developmental stages of the business environment; the working, learning, thinking, and conscious environment. ${ }^{*} p<0.05,{ }^{* *} p<0.01$.

lation between the working environment and spiritual intelligence and its three factors are mostly negative and are not statistically significant.

Table 2 shows the results of the one-way variance analysis, carried out by dependent variables spiritual intelligence (sQ), critical existential thinking (CET), personal meaning production ( $\mathrm{PM}$ ), transcendent awareness (TA), conscious state expansion (CSE), and by the independent variable business environment (Рок).

Results show statistically significant differences between the evolutionary developmental stages of business systems, namely by spiritual intelligence ( $\mathrm{s} Q$ ), personal meaning production ( $\mathrm{PMP}$ ), and conscious state expansion (CSE). The Tukey HSD post hoc test showed that the differences are statistically significant between the working environment and the learning environment, and between the learning environment and the conscious environment at spiritual intelligence $(\mathrm{SQ})$, personal meaning production (PMP), and conscious state expansion (CSE). There were no differences between the averages of critical existential thinking (СET) and transcendent awareness (TA).

Table 3 shows correlations between spiritual intelligence (sQ) and its factors critical existential thinking (СЕT), personal meaning production (PMP), tran- 
Table 2 One-Way ANovA - Differences in Spiritual Intelligence by Work Environments

\begin{tabular}{|c|c|c|c|c|c|}
\hline Item & & (1) & (2) & (3) & (4) \\
\hline \multirow[t]{5}{*}{ SQ } & (a) & 122 & 79.54 & 20.118 & \\
\hline & (b) & 203 & 80.26 & 18.591 & \\
\hline & (c) & 157 & 82.71 & 18.188 & \\
\hline & (d) & 62 & 88.03 & 18.664 & \\
\hline & Sum & 544 & 81.69 & 18.964 & $3.415^{\star} \quad 1-4,2-4$ \\
\hline \multirow[t]{5}{*}{ CET } & (a) & 129 & 22.78 & 6.946 & \\
\hline & (b) & 217 & 22.74 & 6.799 & \\
\hline & (c) & 172 & 23.37 & 6.351 & \\
\hline & (d) & 65 & 24.43 & 6.586 & \\
\hline & Sum & 583 & 23.12 & 6.684 & ns \\
\hline \multirow[t]{5}{*}{ PMP } & (a) & 129 & 17.54 & 4.150 & \\
\hline & (b) & 215 & 17.70 & 3.874 & \\
\hline & (c) & 175 & 18.44 & 3.854 & \\
\hline & (d) & 66 & 19.59 & 3.827 & \\
\hline & Sum & 585 & 18.10 & 3.968 & $5.231^{\star \star \star} 1-4,2-4$ \\
\hline \multirow[t]{5}{*}{ TA } & (a) & 126 & 24.30 & 5.603 & \\
\hline & (b) & 210 & 24.31 & $5 \cdot 513$ & \\
\hline & (c) & 173 & 24.94 & 5.648 & \\
\hline & (d) & 68 & 26.18 & 5.810 & \\
\hline & Sum & 577 & 24.72 & 5.626 & ns \\
\hline \multirow[t]{5}{*}{$\operatorname{CSE}$} & (a) & 130 & 14.82 & 5.116 & \\
\hline & (b) & 215 & 15.09 & 4.628 & \\
\hline & (c) & 174 & 15.75 & 4.604 & \\
\hline & (d) & 69 & $17 \cdot 32$ & 4.539 & \\
\hline & Sum & 588 & 15.49 & $4 \cdot 771$ & $5.010^{\star *} 1-4,2-4$ \\
\hline
\end{tabular}

Notes Column headings are as follows: (1) sample size, (2) average, (3) standard deviance, (4) variance ratio, (5) - differences between categories after post hoc analysis. Row headings are as follows: (a) working environment, (b) learning environment, (c) thinking environment, (d) conscious environment. Displayed are the dependent derived variables SQ - spiritual intelligence, CET - critical existential thinking, PMP - personal meaning production, TA - transcendent awareness, CSE - conscious state expansion and the independent variable POK - business environments, which has four values: working environment, learning environment, thinking environment, and conscious environment. The Tukey HSD test was used for the post hoc analysis. ${ }^{*} p<0.05,{ }^{* *} p<$ $0.01,{ }^{* * *} p<0.001$, ns - no statistically significant differences.
Table 3 Correlations between the Variable Business Environments and Spiritual Intelligence

\begin{tabular}{lcccccc}
\hline Item & POK & SQ & CET & PMP & TA & CSE \\
\hline POK & - & & & & & \\
SQ & $0.125^{\star *}$ & - & & & & \\
CET & 0.068 & $0.902^{* *}$ & - & & & \\
PMP & $0.152^{\star *}$ & $0.857^{* *}$ & $0.652^{\star *}$ & - & & \\
TA & $0.095^{*}$ & $0.939^{* *}$ & $0.789^{\star *}$ & $0.786^{* *}$ & - & \\
CSE & $0.147^{\star *}$ & $0.882^{* *}$ & $0.699^{* *}$ & $0.719^{* *}$ & $0.774^{* *}$ & - \\
\hline
\end{tabular}

Notes $N=601$. Displayed are the derived variables SQ - spiritual intelligence, CET - critical existential thinking, PMP - personal meaning production, TA - transcendent awareness, CSE - conscious state expansion, and POK business environments. ${ }^{*} p<0.05,{ }^{* *} p<0.01$.

scendent awareness (TA) and conscious state expansion (CSE), and the derived variable business environments (РОК).

Results show a statistically significant positive correlation between the derived variable business environment (РОк) and spiritual intelligence (sQ) and its factors personal meaning production ( $\mathrm{PMP}$ ), transcendent awareness ( $\mathrm{TA}$ ), and conscious state expansion (CSE).

Visible are also positive intercorrelations between spiritual intelligence (sQ) and its factors critical existential thinking (СЕT), personal meaning production (РмP), transcendent awareness (TA), and conscious state expansion (CSE).

Table 4 shows the results of the one-way variance analysis, namely the statistically significant differences between genders. The table shows that by spiritual intelligence (SQ), critical existential thinking (CET), personal meaning production (PMP), and by transcendent awareness (TA) women had statistically significantly higher average scores, except by the last variable, namely the business environment (РОК), where men had higher scores on average.

Table 5 shows the results of the one-way variance analysis, namely between the levels of education. The table shows that there are statistically significant differences between levels of education by spiritual intelligence ( $\mathrm{SQ}$ ), personal meaning production ( $\mathrm{PMP}$ ), conscious state expansion (CSE), and by business en- 
Table 4 One-Way AnovA - Differences by Variables between Genders

\begin{tabular}{|c|c|c|c|c|c|}
\hline Item & & (1) & (2) & (3) & (4) \\
\hline \multirow[t]{3}{*}{ SQ } & Male & 204 & 77.64 & 18.167 & \\
\hline & Female & 339 & 84.18 & 19.049 & \\
\hline & Sum & 543 & 81.72 & 18.972 & $15.516^{* * *}$ \\
\hline \multirow[t]{3}{*}{ CET } & Male & 222 & 21.54 & 6.356 & \\
\hline & Female & 360 & 24.13 & 6.702 & \\
\hline & Sum & 582 & 23.14 & 6.687 & $21.399^{\star * *}$ \\
\hline \multirow[t]{3}{*}{ PMP } & Male & 221 & 17.52 & 3.969 & \\
\hline & Female & 363 & 18.46 & 3.934 & \\
\hline & Sum & 584 & 18.10 & 3.970 & $7.861^{\star *}$ \\
\hline \multirow[t]{3}{*}{ TA } & Male & 218 & 23.33 & $5 \cdot 348$ & \\
\hline & Female & 358 & 25.56 & 5.641 & \\
\hline & Sum & 576 & 24.72 & 5.632 & $21.952^{\star * *}$ \\
\hline \multirow[t]{3}{*}{ POK } & Male & 226 & 2.46 & 0.934 & \\
\hline & Female & 372 & 2.21 & 0.933 & \\
\hline & Sum & 598 & 2.30 & 0.941 & $10.709^{\star * *}$ \\
\hline
\end{tabular}

Notes Column headings are as follows: (1) sample size, (2) average, (3) standard deviance, (4) variance ratio. Displayed are only the items where statistically significant differences were found. Displayed are the variables SQ - spiritual intelligence, CET - critical existential thinking, PMP - personal meaning production, TA - transcendent awareness, CSE - conscious state expansion, and POK - business environments. ${ }^{* *} p<0.01,{ }^{* * *} p<0.001$.

vironment (рок). In the table we can see that the participants who scored the highest average spiritual intelligence had also achieved the third Bologna level of education. The same applies to the variable personal meaning production (PMP) and to conscious state expansion (CSE). These are the variables that refer to spiritual intelligence. The results also show that the highest average score by depersonalization (DEP) were achieved by those with a secondary level of education, while those with the first level of education scored the highest on average by business environment.

Table 6 shows the correlation between spiritual intelligence (sQ) and its factors critical existential thinking (СET), personal meaning production (Р MP), transcendent awareness (TA), conscious state expansion (CSE), and two dimensions of business environments.
Table 5 One-Way ANOvA - Differences Based on Achieved Level of Education

\begin{tabular}{|c|c|c|c|c|c|c|}
\hline Item & & (1) & (2) & (3) & (4) & (5) \\
\hline \multirow[t]{7}{*}{ SQ } & (a) & 3 & 74.67 & 15.631 & & \\
\hline & (b) & 89 & 81.21 & 19.065 & & \\
\hline & (c) & 162 & 81.44 & 18.879 & & \\
\hline & (d) & 232 & 80.23 & 18.598 & & \\
\hline & (e) & 54 & 89.06 & 19.178 & & \\
\hline & Sum & 540 & 81.61 & 18.915 & $2.542^{\star}$ & $2-5,3-5$, \\
\hline & & & & & & $4-5$ \\
\hline \multirow[t]{7}{*}{ PMP } & (a) & 3 & 14.67 & 4.726 & & \\
\hline & (b) & 98 & 17.72 & 4.104 & & \\
\hline & (c) & 174 & 17.86 & 4.010 & & \\
\hline & (d) & 247 & 18.13 & 3.800 & & \\
\hline & (e) & 58 & 19.45 & 3.844 & & \\
\hline & Sum & 580 & 18.09 & 3.947 & $2.681^{\star}$ & $1-5,2-5$, \\
\hline & & & & & & $3-5,4-5$ \\
\hline \multirow[t]{7}{*}{$\operatorname{CsE}$} & (a) & 3 & 14.00 & 5.196 & & \\
\hline & (b) & 98 & 15.60 & 4.657 & & \\
\hline & (c) & 174 & 15.28 & 4.840 & & \\
\hline & (d) & 249 & 15.13 & 4.574 & & \\
\hline & (e) & 59 & $17 \cdot 32$ & 5.097 & & \\
\hline & Sum & 583 & 15.47 & 4.754 & $2.749^{\star}$ & $2-5,3-5$ \\
\hline & & & & & & $4-5$ \\
\hline \multirow[t]{8}{*}{ POK } & (a) & 3 & 3.67 & 0.577 & & \\
\hline & (b) & 101 & 2.11 & 0.989 & & \\
\hline & (c) & 178 & 2.24 & 0.846 & & \\
\hline & (d) & 252 & 2.31 & 0.954 & & \\
\hline & (e) & 60 & 2.68 & 0.965 & & \\
\hline & Sum & 594 & 2.30 & 0.943 & $5.435^{\star *}$ & $1-2,1-3$ \\
\hline & & & & & & $1-4,2-5$ \\
\hline & & & & & & $3-5,4-5$ \\
\hline
\end{tabular}

Notes Column headings are as follows: (1) sample size, (2) average, (3) standard deviance, (4) variance ratio, (5) - differences between categories after post hoc analysis. Row headings are as follows: (a) primary, (b) secondary, (c) first Bologna, (d) second Bologna, (e) third Bologna. Displayed are only the variables where statistically significant differences were found, namely $S Q$ - spiritual intelligence, CET - critical existential thinking, PMP - personal meaning production, $\mathrm{TA}$ - transcendent awareness, CSE - conscious state expansion, and POK - business environments. The LSD test was used for post hoc analysis. ${ }^{\star} p<0.05,{ }^{* *} p$ $<0.001$ 
Table 6 Correlation between Two Dimensions of Business Environments and Spiritual Intelligence

\begin{tabular}{lll}
\hline Item & $\mathrm{D} 1$ & $\mathrm{D} 2$ \\
\hline SQ & $0.119^{\star *}$ & $0.118^{* *}$ \\
CET & 0.070 & 0.057 \\
PMP & $0.095^{\star}$ & $0.150^{* *}$ \\
TA & $0.086^{*}$ & $0.099^{\star}$ \\
CSE & $0.101^{\star}$ & $0.134^{* *}$ \\
\hline
\end{tabular}

Notes $N=601$. Displayed are the derived variables SQ - spiritual intelligence, CET - critical existential thinking, PMP - personal meaning production, TA - transcendent awareness, CSE - conscious state expansion, D1 - first dimension of business environments, and D2 - second dimension of business environments. ${ }^{\star} p<0.05,{ }^{* *} p<0.01$.

In the first dimension we have the work and learning environments and in the second we have the thinking and conscious environments.

The table also shows statistically significant positive correlations between spiritual intelligence ( $\mathrm{sQ}$ ) and both dimensions of business environments.

Also statistically significant and positive are correlations between personal meaning production (PMP), transcendent awareness (TA) and conscious state expansion (CSE) and both dimensions of business environments.

\section{Discussion}

The paper shows two separate concepts, which at first sight have nothing in common. But if we look closely, we can see that they have at least one common denominator - the human. The human is the one who asks himself whether there is only one type of intelligence built into him, or are there more, and whether or not he is more or less spiritually intelligent. And the human is the one who enabled us to be asking ourselves about different developmental stages of business systems and be able to research them.

With the survey we wanted to research the potential relationship between a human's spiritual intelligence and the developmental stages of business systems. We wanted to know whether spiritual intelligence is different regarding the developmental stages of business systems. That is why we established two hypotheses that relate to the connections between the factors of spiritual intelligence that, according to King and DeCicco (2009), are critical existential thinking (СET), personal meaning production ( $\mathrm{PMP}$ ), transcendent awareness (TA), conscious state expansion (CSE), and the developmental stages of business systems, which are: working environment, learning environment, thinking environment, and conscious environment (Bulc, 2006).

Obtained data shows that spiritual intelligence is connected with various developmental stages of business environments. The data also shows that through developmental stages of business systems the intensity of spiritual intelligence differs.

The first hypothesis predicted that the connection between spiritual intelligence and business systems is positive. A higher average level of spiritual intelligence would therefore be in higher developmental stages of business systems. This can mean two things. One, according to the AS A theory (Schneider, 1987), the more spiritually intelligent people attract each other and stay in developmentally higher business systems, or two, the developmental stage of a business system has an effect on an employee's average level of spiritual intelligence. Results showed that the lowest developmental stage of business systems - the working environment - does not correlate with spiritual intelligence and its factors. The correlation between spiritual intelligence and its factors are first evident with the learning environment and then continue in the next two developmental stages - the thinking and the conscious environment. But the results are not consistent in a sense that the higher developmental stages of the business system would point to higher average developmental stages of spiritual intelligence. This is shown by the correlation between spiritual intelligence and the learning business environment, which is also statistically more reliable than correlation of spiritual intelligence with the thinking and the conscious business environments. Extra evidence for this can be found in the factor critical existential thinking, where the statistically significant correlation was evident only by the learning business environment (Table 1).

The answer to this question is given to us in Table 2, where it can be clearly seen that, on one hand, the 
second hypothesis must be partly confirmed, because spiritual intelligence significantly differs by individual developmental stages of business systems. On the other hand, the differences can be attributed to only two dimensions. In one we have the work and learning environments and in the second we have the thinking and conscious environments (Table 6).

The results also showed statistically significant differences in the level of spiritual intelligence (sQ) by individual developmental stages of business systems $F(3.540)=3.415, p=0.017$. Differences can also be seen by individual factors of spiritual intelligence (see Table 2), by certain variables, between genders (see Table 4 ), and between the achieved levels of education (see Table 5).

Such research has not been done yet, which is why there is no comparable data. But we can say that, roughly, our findings are in compliance with King's (2008) and King's and DeCicco's (2009) findings, as well as with the findings of Yang and $\mathrm{Wu}$ (2009). The latter two also state that social systems have an influence on spiritual intelligence.

Both the above-mentioned concepts - spiritual intelligence and development of business systems - are individually important for the human being, which we proved in a broad sense in this paper.

As with every research, even this one has room for improvement. It is based on the assumption that we will get enough information with the snowball method that will, on the one hand, be useful for understanding and concluding and, on the other hand, that this data will reflect the actual state of the spirit, beliefs, and the aspects of the surveyed phenomenon. Of course, the number of participants can be understood in two ways, especially in a time of saturation, with more or less felicitous and more or less professionally evaluated questionnaires, which are everything but a contribution to the already known. On one hand, there are people who wanted to participate and, on the other, there are people who are interested in the topic.

It is different with our questionnaire. We have meticulously designed in accordance with the theory. We also done a pilot survey on a sample of students, which showed that we are on the right path and that the instrument for measuring spiritual in- telligence is actually valid, reliable, objective, and in accordance with King's (2008) published data. Nevertheless, a word on executing random sampling with big-enough samples is in order.

Future surveys on the topic should also address limitation of the sample being opportunistic and selfselective. In this context also, a distribution of demographic data of the sample does not allow generalisations - we recommend at least a poststratification of gathered data.

We see the limitation of our research in the elements which are based on electronic data collection. But the electronic data collection is also an advantage, as it is more economic in regards to saving money and time.

This contribution is therefore a theoretical and empirical upgrade to the concept of spiritual intelligence within the evolutionary development of business systems. It took place in the Slovenian cultural space, which, in the sense of international comparison, represents a contribution to science.

The research has limitations. Therefore, we can summarise that the results are mostly indicative - they point to connections of spiritual intelligence with business systems and indicate that the spiritual intelligence of participants in different business environments is, indeed, different.

Our set research problem could therefore be expanded in ways by connecting with stress, burnout, and other negative consequences of life and working in business systems. In this context it would be sensible to research whether stress has an influence on spiritual intelligence, is spiritual intelligence a catalyst for stress, and how are these relations in context with individual developmental stages of business systems.

Despite the limitations mentioned, our research is important. Not only for the individuals but also for business systems and leaders of these systems.

As Zohar and Marshall (2000) state, spiritual intelligence is the highest level of human intelligence and as such also combines classical intelligence and emotional intelligence. Positive influences of classical and emotional intelligence are well established in literature (e.g. Goleman, 1995; Ciarrochi et al., 2001; Shen et al., 2008; Mayer et al., 2008); in addition we could learn 
some aspects of spiritual intelligence (Zareei \& Sedrpooshan, 2015). If that is true, then leaders in all business systems should train to heighten their spiritual intelligence and consequently be better leaders, which will in addition change interpersonal relationships between employees and between employees and leaders and that should lead in two directions. First in more advanced business systems, and second in a higher degree of spiritual intelligence of working individuals.

\section{References}

Biernacki, P., \& Waldorf, D. (1981). Snowball sampling: Problems and techniques of chain referral sampling. Sociological Methods \& Research, 10(2), 141-163.

Bulc, V. (2006). Ritmi poslovne evolucije. Vibacom.

Cianciolo, A. T., \& Sternberg, R. J. (2004). Intelligence: A brief history. Wiley-Blackwell.

Ciarrochi, J., Forgas, J. P., \& Mayer, J. D. (2001). Emotional intelligence in everyday life: A scientific inquiry. Psychology Press.

Coyle, J. (2002). Spirituality and health: Towards a framework for exploring the relationship between spirituality and health. Journal of Advanced Nursing, 37 (6), 589-597.

Detterman, D. K. (2009). Intelligence. In Microsoft Student 2009 [DVD]. Microsoft.

Emmons, R. A. (200o). Is spirituality an intelligence? Motivation, cognition and the psychology of the ultimate concern. The International Journal of Psychology and Religion, $10(1), 3-26$.

Faugier, J., \& Sargeant M. (1997). Sampling hard to reach populations. Journal of Advanced Nursing, 26(4), 790797.

Gardner, H. (1995). Razsežnosti uma: teorija o več inteligencah. Tangram.

Gardner, H. (2000). A case against spiritual intelligence. International Journal for Psychology of Religion, 10(1), 2734.

George, L. K., Larson, D. B., Koenig, H. G., \& McCullough, M. E. (200o). Spirituality and health: What we know, what we need to know. Journal of Social and Clinical Psychology, 19(1), 102-116.

Goleman, D. (1995). Emotional intelligence: Why it can matter more than IQ. Bantam.
Gottfredson, L. (1997). Mainstream science on intelligence: An editorial with 52 signatories, history and bibliography. Intelligence, 24(1), 13-23.

Gottfredson, L. (1998). The general intelligence factor. Scientific American, 9(4), 24-29.

James, W. (1902). The varieties of religious experience: A study of human nature. https://csrs.nd.edu/assets/59930/ williams_1902.pdf

Jensen, A. R. (2002). Galton's legacy to research on intelligence. Journal of Biosocial Science, 34(2), 145-172.

King, D. (2008). Rethinking claims of spiritual intelligence: A definition, model, and measure [Unpublished Master's thesis]. Trent University, Peretborough.

King, D., \& DeCicco, T. L. (2009). A viable model and selfreport measure of spiritual intelligence. International Journal of transpersonal Studies, 28(1), 68-85.

MacDonald, D. A. (2000). Spirituality: Description, measurement, and relation to the five factor model of personality. Journal of Personality, 68(1), 153-197.

Mayer, J. D., Roberts, R. D, \& Barasade, S. G. (2008). Human abilities: Emotional intelligence. Annual Review of Psychology, 59(1), 507-536.

Schneider, B. (1987). The people make the place. Personnel Psychology, 40(3), 437-453.

Shen, W., Groves, K. S., \& McEnrue, P. M. (2008). Developing and measuring the emotional intelligence of leaders. Journal of Management Development, 27(2), 225-250.

Sternberg, R. J., \& Salter, W. (1982). Handbook of human intelligence. Cambridge University Press.

Vaughan, F. (2002). What is spiritual intelligence? Journal of Humanistic Psychology, 42(2), 16-32.

Wolman, R. N. (2001). Thinking with your soul: Spiritual intelligence and why it matters. Harmony Books.

Yang, K. P., \& Wu, X. J. (2009). Spiritual intelligence of nurses in two Chinese social systems: A cross-sectional comparison study. Journal of nursing research, 17(3), 189-197.

Zareei, M. H., \& Sedrpooshan, N. (2015). The relationship between spiritual intelligence and components of burnout in female teachers. Occupational Medicine, 6(4), 66-74.

Zohar, D., \& Marshall, I. (200o). Duhovna inteligenca. Učila International. 